\title{
Characterization of Alternaria Species Associated with Leaf Spot Disease of Armoracia rusticana in Serbia
}

\author{
Jovana Blagojević1, Jelena Vukojević ${ }^{2}$, Borko Ivanović ${ }^{\mathbf{3}}$, and Žarko Ivanović ${ }^{1, \dagger}$ \\ ${ }^{1}$ Institute for Plant Protection and Environment, 11000 Belgrade, Serbia \\ ${ }^{2}$ Institute of Botany, Faculty of Biology, University of Belgrade, 11000 Belgrade, Serbia \\ ${ }^{3}$ Agricultural Advisory Service, 32000 Čačak, Serbia
}

\begin{abstract}
Leaf spot diseases caused by Alternaria species have been reported worldwide in plants in the Brassicaceae family. However, there is little information on Alternaria species causing diseases in horseradish. In the present study, 89 Alternaria spp. isolates from Armoracia rusticana, sampled from nine districts in Serbia, were characterized based on their morphology, physiology, and molecular markers. Morphological characterization and molecular analyses based on ITS, GAPDH, Alt a 1 , and $P M$-ATP sequences identified three distinct species associated with the disease: Alternaria brassicae, A. brassicicola, and A. alternata. For all species, growth and sporulation rates at $0,5,10,15,20,25$, 30,35 , and $40^{\circ} \mathrm{C}$ showed a quadratic response, with $A$. alternata having the widest temperature optimum $\left(20\right.$ to $\left.30^{\circ} \mathrm{C}\right)$ while $A$. brassicicola had

artificially wounded and nonwounded leaves were tested. The pathogenicity test identified A. brassicicola and A. brassicae as the main causal agents of horseradish leaf spot disease. Results indicated that young and intact leaves of horseradish and cabbage were less susceptible to infection and also suggested the potential for cross-infection between these two hosts. Haplotype networks showed haplotype uniformity for A. brassicae, two haplotype groups of A. brassicicola, and eight haplotype groups of A. alternata in Serbia and suggest the possible association of some haplotypes with the geographic area. This study is the first to investigate Alternaria leaf spot disease on A. rusticana in Serbia and is the first record of A. brassicicola on horseradish in this country.
\end{abstract} higher optimum temperatures $\left(20\right.$ to $25^{\circ} \mathrm{C}$ ) than A. brassicae (15 to $20^{\circ} \mathrm{C}$ ). To gain a better understanding of the pathogenicity of these species, the influence of leaf age, host susceptibility, and ability to infect
Keywords: horseradish, Alternaria brassicicola, A. brassicae, A. alternata, fungi, vegetables, pathogen diversity
Armoracia rusticana Gaertn. May \& Scherb. (fam. Brassicaceae) is a well-known commercially cultivated perennial crop throughout Europe, Russia, and North America, due to its culinary and medicinal uses (Agneta et al. 2013). The root of A. rusticana (horseradish) contains high concentrations of sulfur compounds that have been shown to act against soil-borne and human pathogens, and exhibit anticancer, antioxidative, and detoxification properties (Li and Kushad 2004; Tedeschi et al. 2011; Verhoeven et al. 1997). Horseradish, unlike other crucifers, is densely planted from the previous year's lateral roots, and is grown during a long vegetation season, extending from early spring to late autumn. However, even discreet scars in the plant tissue, caused by plant pathogens, can reduce marketable yield $(\mathrm{Yu}$ et al. 2016).

In Serbia, horseradish is grown on 1,500 ha with a yield averaging 8 t/ha. Cultivation and selection of wild horseradish plants have a long tradition, and a particular ecotype called "Novosadski," typical of the province of Vojvodina, is famous for its quality (Perlaki and Djurovka 2009).

The production of horseradish can be affected by several foliar diseases such as: Cercospora leaf spot (Cercospora armoraciae), Ramularia leaf spot (Ramularia armoraciae), Septoria leaf spot (Septoria armoraciae), and bacterial leaf spot caused by Xanthomonas campestris pv. armoraciae (Eastburn and Chang 1994; Gorecka and Lehmann 2001; Percich and Johnson 1990; Yu and Babadoost 2013).

${ }^{\dagger}$ Corresponding author: Ž. Ivanović; zarko.ivanovic@yahoo.com

Funding: This work was supported by the Ministry of Education, Science and Technological Development, Republic of Serbia (grant no. 31018).

The author(s) declare no conflict of interest.

Accepted for publication 19 December 2019.

(C) 2020 The American Phytopathological Society
Alternaria leaf spot diseases are widespread and can cause severe damage to economically important plants in the family Brassicaceae (Chauhan et al. 2009). The most important species are Alternaria brassicae (Berk.) Sacc. causing gray leaf spot and Alternaria brassicicola (Schw.) Wiltshire, causing dark leaf spot disease (Kreis et al. 2016). Another related species, Alternaria alternata (Fr.) Keissl, has been frequently isolated from symptomatic leaves and is considered an opportunistic pathogen (Chauhan et al. 2009). Pathogenic Alternaria species also cause necrotic, dark lesions on the leaves and stems in many other agriculturally important crops, such as tomato, potato, citrus, cereals, and oilseed crops (Amatulli et al. 2013; Gannibal et al. 2014; Peever et al. 2004; Saharan et al. 2005). Infective propagules, mycelia and spores that survive on crop debris, seeds, and association with weed hosts in favorable environmental conditions can cause extensive damage to aerial plant parts, resulting in the death of seedlings, loss in yield, and decrease in market value on susceptible brassica hosts (Humpherson-Jones 1985).

Knowing that many Alternaria species are prominent plant pathogens, involved in more than 4,000 Alternaria/host associations (Lawrence et al. 2008), with high isolate variability even within the same species, many attempts have been made to establish identification and classification systems based on morphological, physiological, pathogenic, and genetic methods, but the resulting taxonomy is still unclear (Andrew et al. 2009; Hong et al. 2005; Lawrence et al. 2014; Peever et al. 2004; Pryor and Michailides 2002; Woudenberg et al. 2013; Zhu and Xiao 2015). Advances in molecular techniques, species detection, and identification have helped to elucidate the genetic diversity of Alternaria species (Lawrence et al. 2013; Pryor and Bigelow 2003; Woudenberg et al. 2013, 2014). Molecular sequence analysis of nuclear genes, such as the internal transcribed spacers (ITS) 1 and 2 and intervening 5.8S rDNA, as well as the major allergen precursor (Alt a 1 ), glyceraldehyde-3-phosphate dehydrogenase (GAPDH), and plasma membrane ATPase (PM-ATP), have proven useful for evaluating phylogenetic interspecies relationships (Hong et al. 2005; Woudenberg et al. 2013; Zhu and Xiao 2015). Some phylogenetic studies dispute the contributions of the commonly used branching tree-like diagram as suitable and adequately informative for 
complex evolutionary pathways (Huson and Bryant 2006). Phylogenetic data in the form of haplotype networks sometimes enable better and more detailed insight into genetic processes, such as gene flow and recombination, and they can better explain population ancestry (Leigh and Bryant 2015).

Growth of Alternaria species is affected by different environmental factors, with temperature playing a particularly important role in disease development and epidemiology (Humpherson-Jones and Phelps 1989). Understanding how different temperatures affect pathogen distribution and disease outbreaks might provide valuable data for developing disease management strategies (Pleysier et al. 2006; Shaw et al. 1990). There is little available data on phylogenetic relations and phenotypic characters of Alternaria species causing leaf spot disease on horseradish in Serbia, as well as in other parts of the world; thus, the goals of this research were to: (i) isolate and identify the Alternaria spp. causing leaf spot disease on A. rusticana in Serbia; (ii) determine their morphological, physiological, and molecular characteristics; (iii) assess the pathogenicity and virulence of Alternaria spp. on horseradish; and (iv) characterize the withinspecies variability of Alternaria species using multilocus sequence analyses.

\section{Materials and Methods}

Sample collection and fungal isolation. From June 2014 to October 2015, symptomatic leaves of horseradish with lesions of different diameter were collected in open field plantations in nine districts in Serbia. Three fields were sampled per district, and for each field, two leaves per plant were collected from 20 plants at equal distances across a diagonal transect of the field, and disease incidence was recorded. Samples were placed in separate paper bags and stored in a field refrigerator at $4^{\circ} \mathrm{C}$ until returning to the lab. Necrotic tissue pieces from the symptomatic leaves were surface disinfested in $1 \%$ sodium hypochlorite for $1 \mathrm{~min}$, rinsed in sterile distilled water (SDW) and transferred on potato dextrose agar (PDA, Difco, Detroit, $\mathrm{MI}$ ), amended with $100 \mathrm{mg} /$ liter of streptomycin sulfate (SigmaAldrich, St. Louis, MO), followed by incubation at $23^{\circ} \mathrm{C}$ for 3 days. Pure cultures were made by taking a single spore under a stereomicroscope and transferring it on PDA for 7 days at $23^{\circ} \mathrm{C}$. Cultures were kept on PDA at $4^{\circ} \mathrm{C}$ in the culture collection of the Institute for Plant Protection and Environment, Belgrade, Serbia. The reference strains of A. brassicicola CBS 118699 and A. brassicae CBS 116528 were used as positive controls.

Morphological characterization. To study the morphological characteristics of the isolates, a 0.5 -cm-diameter mycelia plug was removed from the growing edge of a 5-day-old culture and placed upside down onto the center of a V8 agar (200 ml Campbell V8 juice, $3 \mathrm{~g} \mathrm{CaCO}_{3}, 15 \mathrm{~g}$ agar, and $800 \mathrm{ml}$ sterile distilled water) plate. Cultures were incubated $40 \mathrm{~cm}$ below cool white fluorescent bulbs and illuminated with an $8 \mathrm{~h} / 16 \mathrm{~h}$ photoperiod at $23^{\circ} \mathrm{C}$ (Simmons 2007). Colony diameter was measured every day, and after 7 days, growth rate was calculated, while texture, color, shape, and colony margin were visually characterized. Conidial morphology was observed microscopically at $400 \times$ magnification, whereas the sporulation pattern (length of primary conidiophores, branching types, and origin of branching) was observed under a dissecting scope at $90 \times$ magnification. The length and width of the conidial body and the length and width of the beak were measured $(n=100)$, and the sporulation pattern was analyzed using image analysis software (Motic Images 2000, 1.3 version, Motic Instruments Inc., Canada).

Pathogenicity assays. Pathogenicity assays were performed with the reference strains and all collected isolates on potted 8-week-old horseradish and cabbage plants with a minimum of 10 completely formed leaves in a greenhouse at $25 \pm 3^{\circ} \mathrm{C}$. Cabbage plants were also used to test host specificity because many Brassica spp. are affected by these Alternaria pathogens, and they are often grown commercially in close proximity. Green, healthy, leaves were selected. Young leaves represented the second to fifth leaves, and older leaves represented the sixth to tenth leaves from the top of the plants. Conidial suspensions $\left(10^{6}\right.$ conidia $\left./ \mathrm{ml}\right)$ were diluted in SDW from cultures grown on V8 agar at $23^{\circ} \mathrm{C}$ for 5 days. Plants inoculated only with
SDW were used as negative controls. Two inoculation methods were tested on young and older leaves of the same plant, and three plants each of horseradish and cabbage were used for each isolate. The test was repeated twice. The first method included placing a $20-\mu 1$ drop of the conidial suspension on the intact leaf lamina. The second method involved inoculation by leaf puncturing with sterile needle and placing a 20- $\mu$ l drop of conidial suspension onto the surface of the injured stem of leaf lamina. Relative humidity was maintained between 95 and $100 \%$ for $72 \mathrm{~h}$, and for the next 7 days plants were kept in a growth chamber with an $8 \mathrm{~h} / 16 \mathrm{~h}$ photoperiod, and a $17^{\circ} \mathrm{C} / 23^{\circ} \mathrm{C}$ temperature regime. Inoculated leaves were excised from the plant and the necrotic leaf area was calculated using the program Image J (Schneider et al. 2012). To fulfill Koch's postulates, reisolation was performed from lesions of all plants by placing tissue pieces onto V8 agar. The morphological features of the isolated fungi were compared with the original ones used for inoculation.

Temperature effects on growth and sporulation. Agar plugs (measuring $5 \mathrm{~mm}$ in diameter) of 4-day-old PDA cultures grown at $23^{\circ} \mathrm{C}$ from the growing edge were placed in the center of new PDA plates and incubated with an $8 \mathrm{~h} / 16 \mathrm{~h}$ photoperiod and at 0 , $5,10,15,20,25,30,35$, or $40^{\circ} \mathrm{C}$ in the growth chamber. Three replicate plates were used for each isolate and incubation temperature. The experiment was repeated twice. Every day for 7 days, the colony diameter was measured along two perpendicular axes, and the average was recorded as the radial colony diameter. Daily radial growth rates were calculated as $\mathrm{mm} / \mathrm{day}$. The spore suspension was made by adding $2.5 \mathrm{ml}$ SDW containing $0.01 \%$ Tween-80 to 7-day-old PDA cultures previously incubated at different temperatures, as mentioned above. The mycelia were scraped using a sterile glass spreader and filtered using a muslin cloth to be used as a stock suspension. Only the stock solution of $A$. brassicicola needed to be diluted by taking $100 \mu \mathrm{l}$ into $1 \mathrm{ml}$ of SDW. The number of spores per $\mathrm{ml}$ was counted using a hemocytometer for all isolates.

Data analyses. The collected data were analyzed using analyses of one-way ANOVA in morphological characterization; in the pathogenicity test mixed factorial ANOVA design was used; and a two-way ANOVA model was used to describe growth and sporulation rate influenced by temperature. All of these analyses were conducted in the statistical software package SPSS version 20.0 (SPSS Inc., Chicago, IL). All experiments were performed in a randomized block design, and data between runs of an experiment as well as between values for each isolate of $A$. brassicae, A. brassicicola, and A. alternata were pooled after checking for homogeneity of the experimental error variances. Differences between treatments means were compared by Tukey's honest significance test. For each species, regression analyses were performed using the general linear models (GLM) procedure and regression curves were fitted based on parameter significance $(P<0.05)$ and coefficient of determination $\left(\mathrm{R}^{2}\right)$ to relate the rate of growth and sporulation over different temperature regimes.

DNA extraction and sequence analysis. Approximately $40 \mathrm{mg}$ (dry weight) of aerial mycelium was collected from 7-day-old PDA cultures and used for DNA extraction using the DNeasy Plant Mini Kit (Qiagen, Valencia, CA) following the manufacturer's protocol. The ITS1-5.8S-ITS2 ribosomal gene region was amplified using primer pair ITS1/ITS4 (White et al. 1990) and applying partly modified cycling conditions with the annealing phase changed to $58^{\circ} \mathrm{C}$ for $30 \mathrm{~s}$ and 37 cycles compared with the recommended protocol in Woudenberg et al. (2013). Amplification of the Alt a 1 gene was conducted using primers Alt-for/Alt-rev and thermal conditions described by Hong et al. (2005). For amplification of the GAPDH gene region, primers gpd 1 and gpd 2 were used in conditions of the changed protocol of Berbee et al. (1999) to: initial denaturation at $94^{\circ} \mathrm{C}$ for $1 \mathrm{~min}, 30$ cycles of $94^{\circ} \mathrm{C}$ for $30 \mathrm{~s}, 52^{\circ} \mathrm{C}$ for $45 \mathrm{~s}$, and $72^{\circ} \mathrm{C}$ for $1 \mathrm{~min}$, and a final extension at $72^{\circ} \mathrm{C}$ for $10 \mathrm{~min}$. Amplification of the plasma membrane ATPase was performed using primers ATPDF1 and ATPDR1 as previously described by Lawrence et al. (2013), except the number of cycles was 37 and the annealing temperature was changed to $62^{\circ} \mathrm{C}$ for $30 \mathrm{~s}$. All gene amplifications were performed in a Mastercycler personal model (Eppendorf, Hamburg, 
Table 1. Alternaria spp. isolated from symptomatic leaves of horseradish with: geographic origin, district name, code, GenBank accession numbers and corresponding species-related haplotype group (Alternaria brassicae - I, A. brassicicola - II, and A. alternata - III; 1 to 8 refers to specific haplotype group in a population of certain species). Dashes (-) refer to noncharacterized gene regions.

\begin{tabular}{|c|c|c|c|c|c|c|c|c|c|}
\hline \multirow[b]{2}{*}{ Species } & \multirow[b]{2}{*}{ Region of Serbia } & \multirow[b]{2}{*}{ District } & \multirow[b]{2}{*}{ Locality } & \multirow[b]{2}{*}{ Code } & \multicolumn{4}{|c|}{ GenBank accession numbers } & \multirow[b]{2}{*}{ Haplotype } \\
\hline & & & & & ITS & Alt a 1 & GAPDH & PM-ATP & \\
\hline \multirow[t]{30}{*}{ A. brassicae } & Northern Serbia & Banat & Kikinda & $341 / 4$ & - & - & - & - & $\mathrm{I}-1$ \\
\hline & & & & $342 / 3$ & - & - & - & - & \\
\hline & & & & 349 & - & - & - & - & \\
\hline & & & & $350 / 2$ & - & - & - & - & \\
\hline & & & & $352 / 1$ & KP993532 & KR051383 & KR051391 & MF741793 & \\
\hline & & Bačka & Futog $(\mathrm{N})$ & $356 / 1$ & - & - & - & - & \\
\hline & & & & $359 / 3$ & - & - & - & - & \\
\hline & & & & $380 / 1$ & - & - & - & - & \\
\hline & & & & $380 / 2$ & - & - & - & - & \\
\hline & & & & $380 / 4$ & - & - & - & - & \\
\hline & Belgrade & Belgrade & Borča $(\mathrm{N})$ & $391 / 1$ & - & - & - & - & \\
\hline & & & & $391 / 3$ & - & - & - & - & \\
\hline & & & & $399 / 2$ & - & - & - & - & \\
\hline & & & & $399 / 4$ & - & - & - & - & \\
\hline & & & & $399 / 5$ & - & - & - & - & \\
\hline & Central and Western Serbia & Moravica & Čačak (C) & $442 / 1$ & - & - & - & - & \\
\hline & & & & $444 / 1$ & - & - & - & - & \\
\hline & & Pomoravlje & Jagodina (C) & $407 / 4$ & - & - & - & - & \\
\hline & & & & $407 / 5$ & - & - & - & - & \\
\hline & & & & $420 / 1$ & - & - & - & - & \\
\hline & & & & $420 / 2$ & - & - & - & - & \\
\hline & & Moravica & Guča (C) & $409 / 1$ & - & - & - & - & \\
\hline & & & & 433 & KP993533 & KR051384 & KR051392 & MF741794 & \\
\hline & & Rasina & Stopanja (C) & 437 & - & - & - & - & \\
\hline & & & & $438 / 1$ & - & - & - & - & \\
\hline & & & & $439 / 1$ & - & - & - & - & \\
\hline & South and Eastern Serbia & Jablanica & Leskovac (S) & $434 / 1$ & KP993534 & KR051385 & KR051393 & MF741795 & \\
\hline & & & & 436 & KP993531 & KR051382 & KR051390 & MF741796 & \\
\hline & & Pčinja & Vranje & $340 / 1$ & - & - & - & - & \\
\hline & & & & $340 / 2$ & - & - & - & - & \\
\hline \multirow[t]{39}{*}{ A. brassicicola } & Northern Serbia & Banat & Kikinda (N) & $186 / 2$ & - & - & - & - & II-1 \\
\hline & & & & $183 / 2$ & - & - & - & - & II-2 \\
\hline & & & & $185 / 1$ & - & - & - & - & \\
\hline & & Backa & Futog $(\mathrm{N})$ & $408 / 3$ & KР993530 & KP993537 & KR051388 & MF741797 & II-1 \\
\hline & & & & $406 / 2$ & - & - & - & - & II-2 \\
\hline & & & & $407 / 1$ & - & - & - & - & \\
\hline & Belgrade & Belgrade & Borča (N) & $189 / 1$ & - & - & - & - & II-1 \\
\hline & & & & $186 / 4$ & - & - & - & - & II-2 \\
\hline & & & & $190 / 2$ & - & - & - & - & \\
\hline & Central and Western Serbia & Moravica & Čačak (C) & 410 & - & - & - & - & II-1 \\
\hline & & & & $414 / 2$ & - & - & - & - & \\
\hline & & & & $414 / 3$ & - & - & - & - & \\
\hline & & & & 420 & - & - & - & - & \\
\hline & & & & 421 & - & - & - & - & \\
\hline & & & & 422 & - & - & - & - & \\
\hline & & & & $429 / 3$ & KP993527 & KP993535 & KR051386 & MF741798 & II-2 \\
\hline & & Pomoravlje & Jagodina $(\mathrm{C})$ & $203 / 1$ & - & - & - & - & II-1 \\
\hline & & & & 203/6 & - & - & - & - & \\
\hline & & & & $207 / 2$ & - & - & - & - & \\
\hline & & & & 208 & & - & - & - & \\
\hline & & & & 207/1 & - & - & - & - & II-2 \\
\hline & & & & $208 / 2$ & - & - & - & - & \\
\hline & & Moravica & Guča (C) & $179 / 2$ & - & - & - & - & II-1 \\
\hline & & & & $180 / 1$ & - & - & - & - & \\
\hline & & & & $181 / 3$ & - & - & - & - & \\
\hline & & Rasina & Stopanja (C) & $202 / 1$ & - & - & - & - & \\
\hline & & & & $202 / 2$ & - & - & - & - & \\
\hline & & & & $202 / 5$ & - & - & - & - & \\
\hline & & & & $202 / 6$ & - & - & - & - & \\
\hline & & & & $205 / 1$ & - & - & - & - & \\
\hline & & & & $205 / 5$ & - & - & - & - & \\
\hline & South and Eastern Serbia & Jablanica & Leskovac (S) & $434 / 2$ & KP993529 & KP993538 & KR051389 & MF741799 & \\
\hline & & & & $434 / 3$ & - & - & - & - & \\
\hline & & & & 435 & КР993528 & KP993536 & KR051387 & MF741800 & \\
\hline & & & & $434 / 4$ & - & - & - & - & II-2 \\
\hline & & Pčinja & Vranje (S) & $173 / 1$ & - & - & - & - & II-1 \\
\hline & & & & $176 / 5$ & - & - & - & - & II-1 \\
\hline & & & & $176 / 3$ & - & - & - & - & II-2 \\
\hline & & & & & & & & (Continue & ( next page) \\
\hline
\end{tabular}


Germany) in $25-\mu 1$ reaction volumes containing: 5 ng DNA, $1 \times$ PCR buffer $(20 \mathrm{mM}$ Tris/ $\mathrm{HCl} \mathrm{pH} 8.4,50 \mathrm{mM} \mathrm{KCl}), 1 \mu \mathrm{M}$ of each primer, $2.5 \mathrm{mM} \mathrm{MgCl} 2,0.25 \mathrm{mM}$ of each dNTP, and 1 unit of Taq polymerase (Fermentas, Vilnius, Lithuania). Amplicons were separated in $1 \%$ agarose gels in $0.5 \times$ TBE buffer and visualized by ethidium bromide staining under UV illumination. PCR products were purified by the ethanol precipitation method (QIAquick PCR Purification Kit, Qiagen, Valencia, CA) and then commercially sequenced on an ABI Prism 3700 automated sequencer (Macrogen Inc., Seoul, South Korea). The obtained sequences were edited using FinchTV v.1.4.0 (Geospiza, https://digitalworldbiology.com/FinchTV) and aligned with ClustalW within the MEGA6 software (Tamura et al. 2013). Gene sequences of representative isolates of Alternaria spp. isolated from horseradish were deposited into NCBI GenBank (Table 1). For the haplotype comparison, we used representative numbers of the reference sequences of the Alternaria species corresponding gene regions previously published (Lawrence et al. 2013; Pryor and Bigelow 2003; Pryor and Michailides 2002; Runa et al. 2009; Woudenberg et al. 2013, 2014) (Table 2).
Construction of a phylogenetic tree and haplotype network. Nucleotide sequences of the four analyzed gene regions, ITS, Alt $a$ $1, G A P D H$, and $P M-A T P$, were concatenated and in subsequent phylogenetic analyses treated as a single multilocus genotype. Manual corrections, alignments, and comparisons of the aligned database were performed using CLUSTALW integrated into MEGA6 software (Tamura et al. 2013). The best-fitting nucleotide substitution model used in further phylogenetic analysis was determined using jModeltest 2.1.7 (Darriba et al. 2012) following the Akaike information criterion (AICc). Maximum likelihood phylogeny was reconstructed using MEGA6 software, applying 1,000 bootstrap replicates and pairwise deletion (Tamura et al. 2013). Bayesian-based phylogenetic analysis was performed in MrBayes (ver. 3.1.2) (Ronquist and Huelsenbeck 2003) using the following settings: two Markov Chain Monte Carlo (MCMC) runs executing 1 million generations and sampling every 100 generations. A standard deviation of the split frequencies was checked until it reached a value below 0.01 (applying default burn-in $=25 \%$ ). The convergence of the MCMC chains and their stationarity were checked using Tracer 1.5

Table 1. (Continued from previous page)

\begin{tabular}{|c|c|c|c|c|c|c|c|c|c|}
\hline \multirow[b]{2}{*}{ Species } & \multirow[b]{2}{*}{ Region of Serbia } & \multirow[b]{2}{*}{ District } & \multirow[b]{2}{*}{ Locality } & \multirow[b]{2}{*}{ Code } & \multicolumn{4}{|c|}{ GenBank accession numbers } & \multirow[b]{2}{*}{ Haplotype } \\
\hline & & & & & ITS & Alt a 1 & GAPDH & PM-ATP & \\
\hline \multirow[t]{20}{*}{ A. alternata } & Northern Serbia & Banat & Kikinda (N) & $973 k$ & - & - & - & - & III-6 \\
\hline & & & Kikinda (N) & $194 / 1$ & - & - & - & - & III-8 \\
\hline & & Bačka & Futog $(\mathrm{N})$ & $411 / 3$ & KR051269 & KR051265 & KR051397 & MF741783 & III-1 \\
\hline & & & Futog $(\mathrm{N})$ & $400 / 4$ & MF741805 & MF741811 & MF741817 & MF741790 & III-5 \\
\hline & & & Futog $(\mathrm{N})$ & $400 / 2$ & - & - & - & - & III-8 \\
\hline & & & Futog $(\mathrm{N})$ & $400 / 3$ & MF741803 & MF741809 & MF741815 & MF741789 & \\
\hline & Belgrade & Belgrade & Borča $(\mathrm{N})$ & $372 / 3$ & MF741804 & MF741810 & MF741816 & MF741785 & III-6 \\
\hline & & & Borča $(\mathrm{N})$ & $368 / 1$ & MF741802 & MF741808 & MF741814 & MF741787 & III-7 \\
\hline & & & Borča $(\mathrm{N})$ & $368 / 2$ & - & - & - & - & III-8 \\
\hline & Central and Western Serbia & Moravica & Čačak (C) & $429 / 1$ & - & - & - & - & III-1 \\
\hline & & & Čačak (C) & $429 / 2$ & KR051266 & KP993539 & KR051394 & MF741788 & III-3 \\
\hline & & Pomoravlje & Jagodina $(\mathrm{C})$ & $982 / 5$ & - & - & - & - & III-1 \\
\hline & & & Jagodina $(\mathrm{C})$ & $171 / 3$ & - & - & - & - & \\
\hline & & & Jagodina $(\mathrm{C})$ & $982 / 2$ & KR051268 & KP993541 & KR051395 & MF741791 & III-2 \\
\hline & & & Jagodina $(\mathrm{C})$ & $982 / 3$ & KR051267 & KP993540 & KR051396 & MF741792 & \\
\hline & & & Jagodina (C) & $51 / 3$ & - & - & - & - & III-4 \\
\hline & & Moravica & Guča (C) & $986 \mathrm{a}$ & MF741806 & MF741812 & MF741818 & MF741784 & III-4 \\
\hline & & Rasina & Stopanja (C) & $980 / 1$ & - & - & - & - & III-1 \\
\hline & & & Stopanja (C) & $999 \mathrm{k}$ & - & - & - & - & III-2 \\
\hline & South and Eastern Serbia & Jablanica & Leskovac (S) & 452 & MF741801 & MF741807 & MF741813 & MF741786 & III-2 \\
\hline
\end{tabular}

Table 2. Species used for phylogenetic analyses in this study, their sources, and GenBank accession numbers

\begin{tabular}{|c|c|c|c|c|c|c|}
\hline \multirow[b]{2}{*}{ Species } & \multirow[b]{2}{*}{ Country } & \multirow[b]{2}{*}{ Source ${ }^{a}$} & \multicolumn{4}{|c|}{ GenBank accession numbers } \\
\hline & & & ITS & Alt a 1 & GAPDH & PM-ATP \\
\hline Alternaria alternata & India & EGS 34-016 & AF347031 & KP275691 & AY278808 & JQ671874 \\
\hline A. arborescens & U.S.A. & EGS $39-128$ & AF347033 & AY563303 & AY278810 & JQ671880 \\
\hline A. tenuissima & U.K. & EGS 34-015 & AF347032 & KP275690 & AY278809 & JQ671875 \\
\hline A. brassicae & U.S.A. & EGS $38-032$ & JQ693663 & AY563309 & AY562414 & JQ671847 \\
\hline A. brassicicola & U.S.A. & EEB 2232 & AF229652 & AY563311 & AY278813 & JQ671843 \\
\hline A. dauci & U.S.A. & ATCC 36613 & AF229466 & AY563292 & AY278803 & JQ671907 \\
\hline A. infectoria & U.K. & EGS 27-193 & AF347034 & FJ266502 & AY278793 & JQ646454 \\
\hline A. gypsophilae & Denmark & CBS 107.41 & KC584199 & KJ718688 & KC584118 & JQ671859 \\
\hline A. longipes & U.S.A. & EGS 30-033 & AY278835 & AY278811 & AY278811 & JQ671864 \\
\hline A. porri & U.S.A. & ATCC 58175 & AF229470 & AY563296 & AY278797 & JQ671901 \\
\hline A. radicina & France & ATCC 96831 & AF229472 & AY563286 & AY278797 & JQ671851 \\
\hline A. selini & Saudi Arabia & ATCC 25198 & AF229455 & FJ266504 & AY278800 & JQ671853 \\
\hline A. smyrnii & U.K. & ATCC 37093 & AF229456 & AY563289 & AY278801 & JQ671852 \\
\hline A. solani & Mexico & ATCC 58177 & AF229456 & AY563299 & AY278807 & JQ671898 \\
\hline A. tomatophila & U.S.A. & CBS 109156 & AM237289 & JQ646431 & JQ646047 & JQ671748 \\
\hline A. zinnae & Hungary & CBS 118.44 & KJ718264 & KJ718771 & JQ646361 & JQ671937 \\
\hline Stemphylium callistephi & - & EEB 1055 & AF229482 & AY563276 & AY278822 & JQ671769 \\
\hline
\end{tabular}

a ATCC, American Type Culture Collection, Manassas, VA 20108; EEB, EE Butler, Department of Plant Pathology, University of California, Davis, CA 95616; EGS, EG Simmons, Mycological Services, Crawfordsville, IN 47933; CBS, Centraalbureau voor Schimmelcultures, Royal Netherlands Academy of Arts and Sciences, Uppsalalaan 8,3584 CT Utrecht, the Netherlands. 
(Rambaut and Drummond 2009). The phylogenetic tree was visualized using FigTree 1.4 (Rambaut 2012). To achieve a better resolution for the evolutionary relations among Alternaria isolates from horseradish, the genealogical network was obtained in TCS version 1.21 (Clement et al. 2000) using statistical parsimony with a confidence level of $95 \%$ to associate haplotype groups and indicate possible geographic separation on population structure. The sequence of Stemphylium calistephi served as outgroup taxa based on results from Lawrence et al. (2013).

\section{Results}

Sample collection and fungal isolations. Leaves of infected horseradish plants had gray to dark brown or black lesions with a surrounding chlorotic halo. The diameter of the lesions ranged from 3 to $15 \mathrm{~mm}$, and larger lesions had a darker margin and concentric rings. Symptoms were more severe on the older leaves and the leaves closest to the soil were often $100 \%$ symptomatic. Symptomatic plant material was collected from nine locations in Serbia, including the northern region (Futog, Kikinda), Belgrade region (Borča), the central and western region (Jagodina, Cačak, Guča, Stopanja), and the southern and eastern Serbia region (Leskovac, Vranje) (Fig. 1). A total of 89 Alternaria isolates were obtained from infected leaf samples (Table 1). The disease incidence ranged from 30 to $50 \%$ for all surveyed fields, and the presence of Alternaria sp. was confirmed in every sampled field.

Morphological characterization. All 89 Alternaria spp. isolates were classified into three distinct morphological groups. The first group contained 30 isolates based on morphological traits of conidia and the sporulation pattern was identified as A. brassicae (Fig. 2). Isolates on V8 agar formed cottony, white or light brown mycelium on the surface; colonies were circular, and the margin varied in color and width (Fig. 2D). Growth rates were moderate and slower than the other two species groups and ranged from 3 to $6 \mathrm{~mm} /$ day. For white and light brown mycelial types, abundant sporulation was observed 3 days after aerial mycelium was scraped with sterile needle from the surface (Fig. 2C). Conidia were formed singly or in chains of 2 or 3 on mostly unbranched, septate conidiophores, ranging from 90 to $160(126.67 \pm 18.2) \mu \mathrm{m}$ in length. Conidia ranged from 116.3 to $193.3 \mu \mathrm{m}(156.08 \pm 20.55) \times 10.5$ to $15.5 \mu \mathrm{m}(13.03 \pm 1.26)$ in size and were typically brown in color and obclavate in shape (Fig. $2 \mathrm{E}, \mathrm{F})$. The number of transverse and longitudinal septa of conidia varied from 3 to 16 and 0 to 5 , respectively. The size of the beak ranged from 53.4 to $77.4 \mu \mathrm{m}(66.3 \pm 6.2) \times 6.6$ to $12.3 \mu \mathrm{m}(9.42$ $\pm 1.4)$. There were no statistically significant differences in the

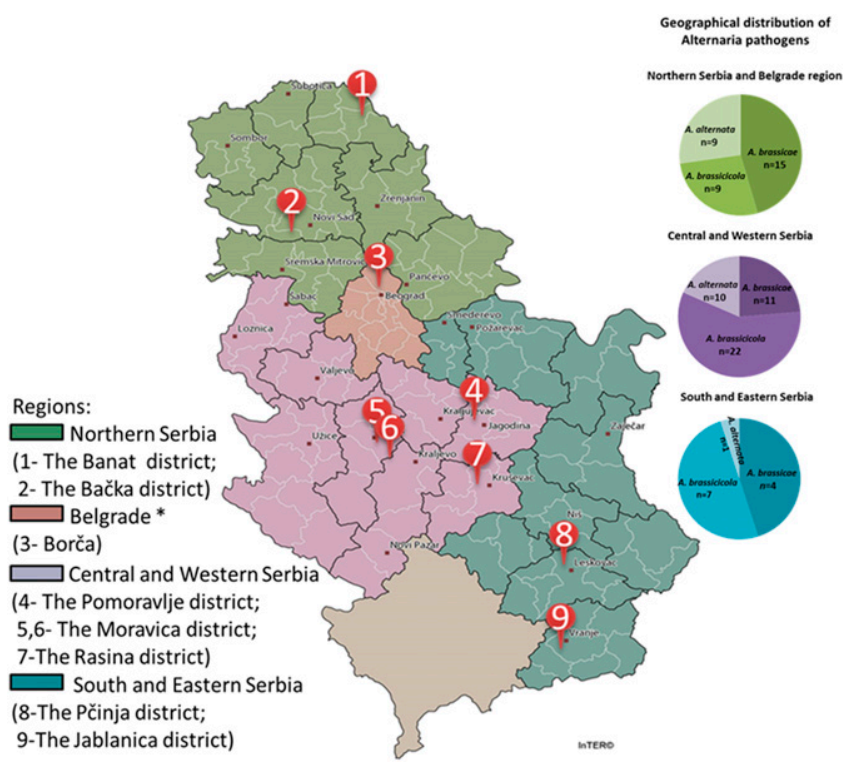

Fig. 1. Geographic regions of Serbia where diseased horseradish plants were collected. growth rate $(P=0.468)$, conidiophore length $(P=0.072)$, in length $(P=0.751)$ and width $(P=0.649)$ of the conidial body, or length $(P=0.446)$ and width $(P=0.311)$ of the beak among the isolates.

The second group, consisting of 39 isolates, had highly uniform, circular, brown-black, cottony colonies with a brownish border (Fig. 3D). Branched conidiophores formed concentric rings over the entire colony surface. The colonies ranged from 15 to $160 \mu \mathrm{m}$ in length, and chains of up to 20 conidia were observed (Fig. 2C, E). Daily growth rates ranged from 7 to $8 \mathrm{~mm}$. The colony color on the surface and the reverse side was uniform. Conidia ranged from 28.3 to $33.1 \mu \mathrm{m} \times 10.2$ to $11.3 \mu \mathrm{m}$ in size and were typically ellipsoid, ovoid, or somewhat obclavate. The dimensions of the beak were 3.6 to $6.3 \mu \mathrm{m} \times 2.2$ to $5.6 \mu \mathrm{m}$. The numbers of transversal and longitudinal septa of conidia varied from 1 to 8 and 0 to 4 , respectively, but longitudinal septa were rare and occurred only in $2 \%$ of conidia (Fig. 3F). Based on these features, isolates in this group were identified as A. brassicicola (Fig. 3) (Simmons 2007). There were no statistically significant differences in growth rate $(P=0.095)$, conidiophore length $(P=0.237)$, length $(P=0.395)$ and width $(P=0.353)$ of the conidial body, or length $(P=0.207)$ and width $(P=0.518)$ of the beak among the isolates.

The third group, consisting of 20 isolates, was most variable in morphology. The mycelium had a cottony, feathery texture, and the color consisted of differing shades of gray-green (Fig. 4A). Colony margins varied, and concentric rings were observed on the surface of all colonies. Daily growth rates ranged from 8 to $11 \mathrm{~mm}$. Primary conidiophores ranged from 27 to $85 \mu \mathrm{m}$, and conidia were produced in chains of 8 to 12 . Numerous secondary and occasionally tertiary chains branched from apical and intercalary cells (Fig. 4B). Conidia were obclavate to long-ellipsoid in shape, measured small or moderate in size, 28.3 to $35.9 \mu \mathrm{m} \times 9.5$ to $13.6 \mu \mathrm{m}$, and had 1 to 8 transversal and 0 to 4 longitudinal septa (Fig. 4C). The beak size varied from 2.7 to $7.9 \mu \mathrm{m} \times 2.9$ to $6.6 \mu \mathrm{m}$. Based on these characteristics, isolates were identified as A. alternata. There were no statistically significant differences in the growth rate $(P=0.097)$, conidiophore length $(P=0.329)$, length $(P=0.702)$ and width $(P=0.089)$ of the conidial body, or length $(P=0.766)$ and width $(P=0.390)$ of the beak among the isolates.

Pathogenicity assays. Horseradish and cabbage plants developed first symptoms 3 days after inoculation by both methods used, exhibiting small necrotic lesions with chlorotic halos (Fig. 5). Leaf spots on horseradish plants were gray or brownish and very similar for A. brassicae and A. brassicicola. On cabbage plants, A. brassicae produced gray to light brown lesions, while those for A. brassicicola were light or dark brown. After 7 days, enlarging spots coalesced and looked similar to those on naturally infected leaves. After 14 days, extensive blight of the leaf surface was observed. A. alternata did not cause necrotic lesions on horseradish plants, and chlorosis was only occasionally present on the wounded leaf surface.

All fungal isolates of $A$. brassicae and A. brassicicola as well as the reference strains were pathogenic to horseradish and cabbage plants. A mixed factorial ANOVA revealed a statistically significant three-way interaction between species, host, and inoculation method $\left(\mathrm{F}_{2,168}=3.963, P=0.021\right)$, and species, host, and leaf age $\left(\mathrm{F}_{2,168}=\right.$ $46.650, P=0.003)$. The statistical significance of a simple two-way interaction and a simple simple main effect was accepted at a Bonferroni-adjusted alpha level of 0.025 . There were statistically significant simple two-way interactions between host and inoculation method, host and leaf age for A. brassicae $\left(\mathrm{F}_{1,58}=15.812, P=\right.$ $0.004 ; \mathrm{F}_{1,58}=57.452, P=0.003 ; \mathrm{F}_{1,58}=649.380, P=0.003$; respectively), A. brassicicola $\left(\mathrm{F}_{1,72}=22.553, P=0.001 ; \mathrm{F}_{1,72}=115.866\right.$, $P=0.000 ; \mathrm{F}_{1,72}=835.940, P=0.000 ;$ respectively) and A. alternata $\left(\mathrm{F}_{1,38}=128.781, P=0.001 ; \mathrm{F}_{1,38}=201.101, P=0.000 ; \mathrm{F}_{1,38}=\right.$ $128.781, P=0.000$; respectively). Simple two-way interaction between inoculation method and leaf age was statistically significant only for pathogenicity of $A$. alternata $\left(\mathrm{F}_{1,38}=33.378, P=0.004\right)$. Statistically significant simple simple main effect of leaf age was recorded for $A$. brassicae and $A$. brassicicola inoculated on unwound surface of horseradish $\left(\mathrm{F}_{1,168}=10.059, P=0.002 ; \mathrm{F}_{1,168}=54.961\right.$, $P=0.002$; respectively $)$ and cabbage $\left(\mathrm{F}_{1,168}=62.654, P=0.000\right.$; 
$\mathrm{F}_{1,168}=688.482, P=0.000$; respectively). This simple simple main effect of leaf age was also revealed for A. brassicae and A. brassicicola inoculated on wound surface of horseradish $\left(\mathrm{F}_{1,168}=8.993, P=\right.$ $0.003 ; \mathrm{F}_{1}, 168=54.961 P=0.002$; respectively) and cabbage $\left(\mathrm{F}_{1,168}=55.453, P=0.000 ; \mathrm{F}_{1,168}=13.994, P=0.000\right.$; respectively). For A. alternata, significant simple simple main effect of leaf age was recorded for wounded leaves of cabbage $\left(\mathrm{F}_{1,168}=1.591, P=\right.$ 0.020 ). Statistically significant simple simple main effect of the inoculation method was revealed for $A$. brassicicola on old and young leaves of cabbage $\left(\mathrm{F}_{1,168}=51.926, P=0.002 ; \mathrm{F}_{1,168}=80.889\right.$, $P=0.014$; respectively $)$ and young leaves of horseradish $\left(\mathrm{F}_{1,168}=\right.$ 17.584, $P=0.002)$ and for $A$. brassicae on old and young cabbage leaves $\left(\mathrm{F}_{1,168}=27.156, P=0.004 ; \mathrm{F}_{1,168}=28.792, P=0.001\right.$; respectively). Statistically significant simple simple main effect of the host was revealed for $A$. brassicae and A. brassicicola intact young $\left(\mathrm{F}_{1,168}=186.806, P=0.001 ; \mathrm{F}_{1,168}=540.690, P=0.000\right.$; respectively) and old leaves $\left(\mathrm{F}_{1,168}=73.544, P=0.001 ; \mathrm{F}_{1,168}=505.447\right.$, $P=0.000$; respectively). In treatments where the leaf surface was previously wounded, there was also a statistically significant simple main effect of the host for $A$. brassicae and A. brassicicola inoculated on young $\left(\mathrm{F}_{1,168}=113.922, P=0.001 ; \mathrm{F}_{1,168}=257.436, P=0.000\right.$; respectively) and old leaves $\left(\mathrm{F}_{1,168}=73.366, P=0.001 ; \mathrm{F}_{1,168}=\right.$ 393.200, $P=0.000$; respectively) but for A. alternata this effect was significant only on wounded old leaves $\left(\mathrm{F}_{1,168}=1.388, P=\right.$ 0.021) (Fig. 6). In the absence of wounding, A. brassicicola was more virulent on both hosts (3.6 and $15.1 \%$ leaf area was symptomatic on old and 0.8 and $7.34 \%$ on young horseradish and cabbage leaves, respectively, for A. brassicae, and 10.3 and $37.3 \%$ for old and 2.3 and $14.1 \%$ for young leaves respectively, for $A$. brassicicola). The average leaf area affected after wound inoculation with A. brassicicola was $12.3 \%$ for old and $6.4 \%$ for young horseradish leaves and $48.2 \%$ for old and $20.8 \%$ for young cabbage leaves. After wound inoculation with A. brassicae, $6.9 \%$ of the leaf area of the old leaves and $1 \%$ of the area of young leaves were affected on horseradish plants, and $23.7 \%$ of the area of old leaves and $11.78 \%$ of the area of young leaves were affected on cabbage plants. A. alternata only caused minor symptoms on old cabbage leaves, and the necrotic area was approximately $1 \%$ of the total leaf area after non-wound inoculation and $1.5 \%$ after wound inoculation. On the horseradish, only minor changes in leaf color were observed after inoculation with A. alternata. No symptoms were observed on any noninoculated plants. The pathogens were reisolated and found to be morphologically identical to the original isolates.

Effect of temperature on pathogen growth and sporulation. For all species, temperature significantly affected the amount of sporulation and mycelial growth rate $\left(\mathrm{F}_{12,152}=43.85, P=0.01\right.$, partial $\eta^{2}=0.78$ ) following a quadratic response (Fig. 7). Reference strains CBS 118699 and CBS 116528 exhibited sporulation patterns similar to the investigated isolates A. brassicicola and A. brassicae, respectively. The optimum temperature for isolates of $A$. brassicae from horseradish was from 15 to $20^{\circ} \mathrm{C}$ (with no significant differences between the two temperatures, $P=0.087)$, with an average radial growth of $4 \mathrm{~mm} /$ day and sporulation of $0.22 \times 10^{6}$ conidia/ml. None of the $A$. brassicae isolates grew or produced spores at 0,35 , or $40^{\circ} \mathrm{C}$; some growth occurred at $30^{\circ} \mathrm{C}$, but no sporulation occurred. Isolates of $A$. brassicicola and A. alternata did not grow or produce spores at 0 or $40^{\circ} \mathrm{C}$. A. brassicicola isolates showed maximum radial growth and sporulation at 20 to $25^{\circ} \mathrm{C}$ (without significant differences between the two temperatures, $P=0.107)$ and grew an average of $6 \mathrm{~mm} /$ day and produced $2.74 \times 10^{6}$ conidia $/ \mathrm{ml}$. Isolates of $A$. alternata grew $7 \mathrm{~mm} /$ day and produced $1.12 \times 10^{6}$ conidia/ml between 20 and $30^{\circ} \mathrm{C}$. Growth decreased at $35^{\circ} \mathrm{C}$ but was still higher than for the other two species.

Phylogenic relationships among isolates of Alternaria spp. from horseradish. When ITS, Alt a $1, G A P D H$, and PM-ATP
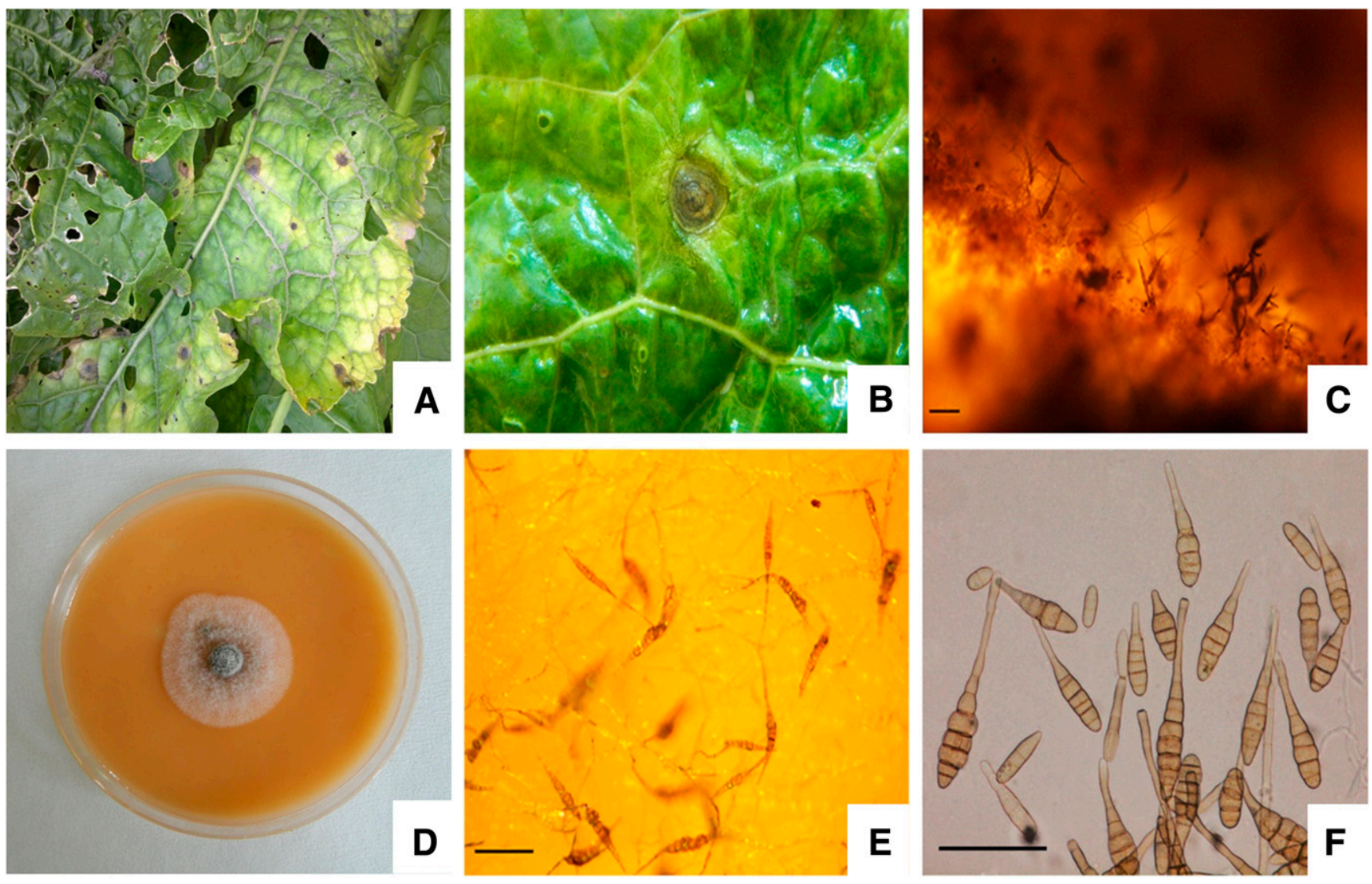

Fig. 2. Alternaria brassicae. A, Symptoms of leaf spots on horseradish. B, Concentric rings on lesions. C, Mycelia and conidia on a necrotic spot. D, 7-day-old culture on V8 medium. E, Sporulation pattern on V8 medium. F, Conidia. Bars: $100 \mu \mathrm{m}$. 
sequences of the Alternaria isolates from horseradish were subjected to a BLAST search in NCBI GenBank, isolates were assigned to $A$. brassicae, A. brassicicola, or A. alternata (Table 1), which was in agreement with previous efforts to identify these pathogens based on morphological characterization. Further phylogenetic analyses for the four concatenated gene loci were performed on a set of different haplotypes, considering that morphological and pathogenicity tests did not assist in any differentiation by intra species groups. Among 89 samples, a total of 11 haplotypes were identified. A single haplotype was identified among isolates of A. brassicae. Two closely related haplotypes were present among isolates of $A$. brassicicola that showed differences in the GAPDH gene sequences, whereas eight were found among isolates of A. alternata. A. alternata isolates were identified based on $P M-A T P$ sequences.

The Akaike information criterion revealed the Tamura-Nei model with invariable sites and gamma distribution $(\mathrm{TRN}+\mathrm{I}+\mathrm{G})$ as the bestfit model. Both maximum likelihood and Bayesian statistic-based phylogenetic analyses revealed almost identical tree topology (Fig. 8). The parameters for the Bayesian analyses were the following: Lset base $=$ $(0.23450 .30500 .2396) \mathrm{nst}=6 \mathrm{rmat}=\left(\begin{array}{ll}1.0000 & 2.89091 .00001 .0000\end{array}\right.$ 6.2411 ) rates $=$ gamma shape $=0.6490$ ncat $=4$ pinvar $=0.4350$.

A reconstructed dendrogram revealed five major clades with high or moderate ML bootstrap and Bayesian posterior support (Fig. 8). Clade I contained eight $A$. alternata isolates in several subclades:
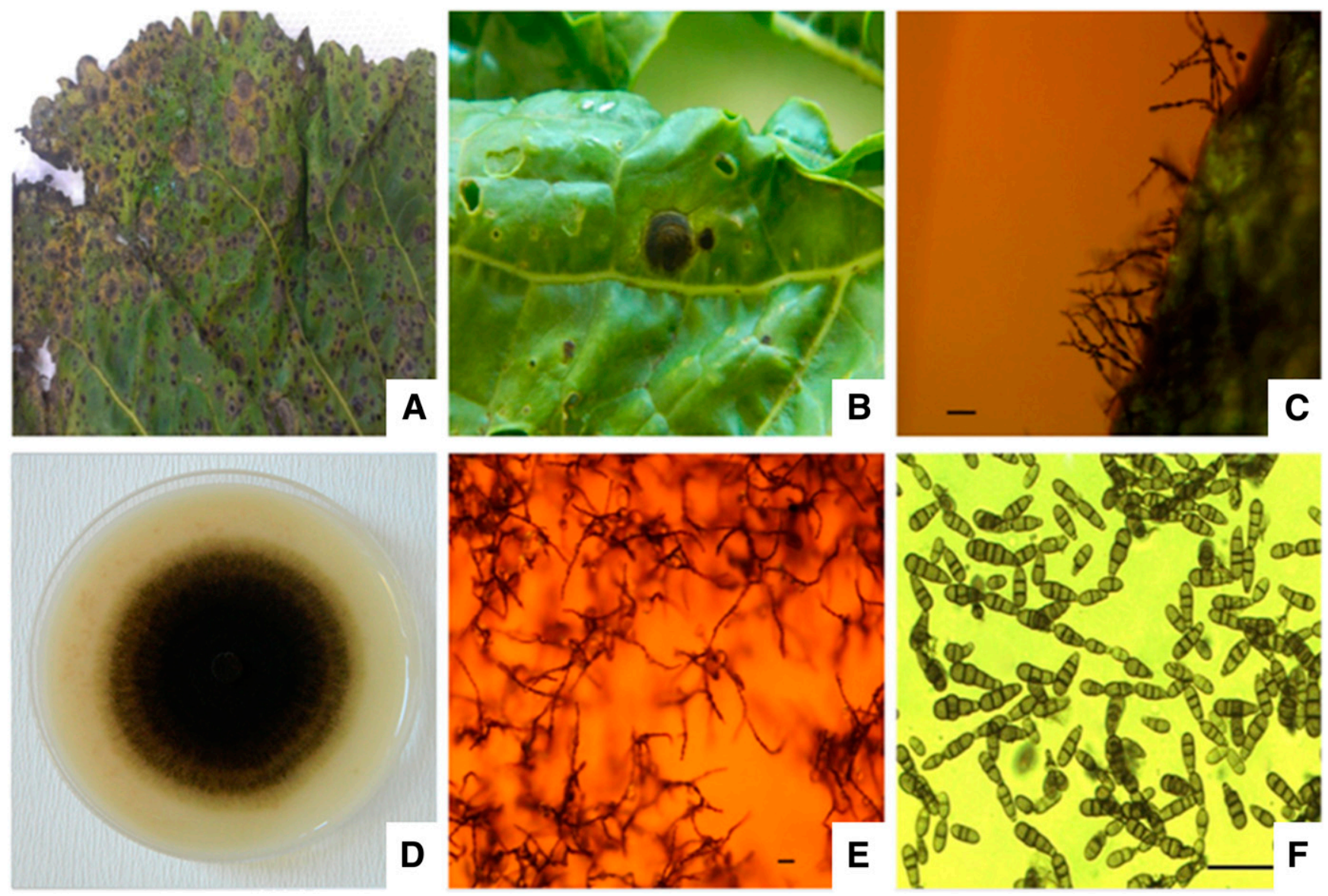

Fig. 3. Alternaria brassicicola. A, Symptoms of leaf spots on horseradish. B, Concentric rings on lesions. C, Mycelia and conidia on a necrotic spot. D, 7-day-old culture on V8 medium. E, Sporulation pattern on V8 medium. F, Conidia. Bars: $50 \mu \mathrm{m}$.
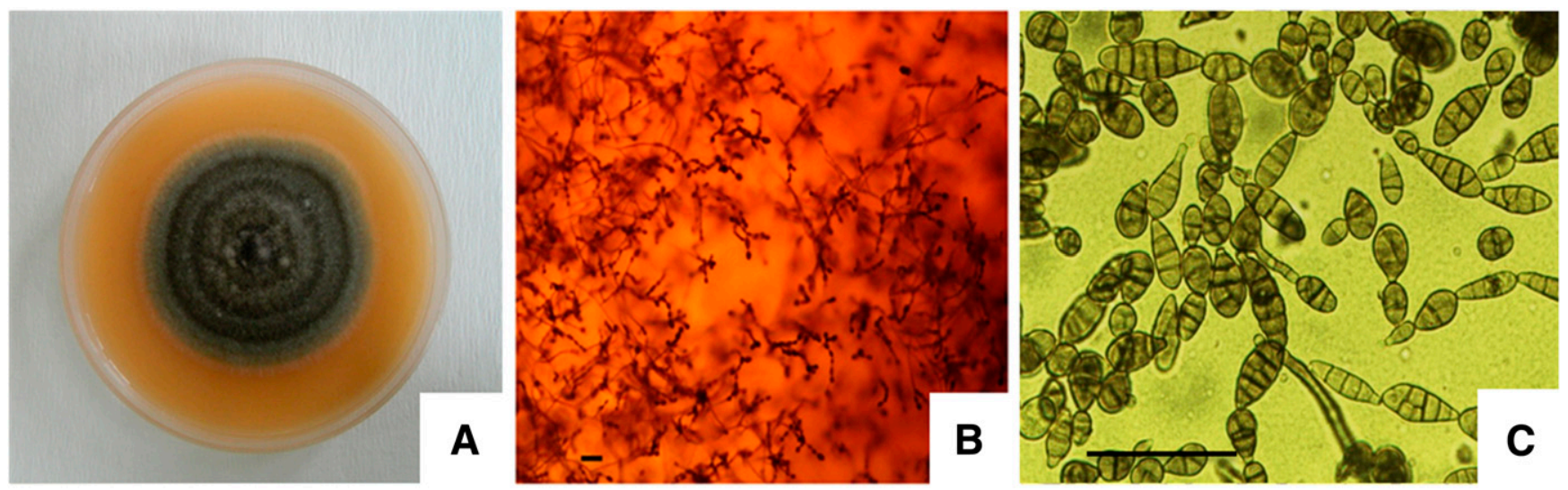

Fig. 4. Alternaria alternata. A, 7-day-old culture on V8 medium. B, Sporulation pattern on V8 medium. C, Conidia. Bars: $50 \mu \mathrm{m}$. 
the first subclade included isolates 452 and 429/2, and isolates $986 a$ and $411 / 3$ grouped in the same subclade; isolates $372 / 3$ and $400 / 4$, and isolates 400/3 and 368/1 formed another two subclades. Highly supported clade (100/89) has shown that all A. alternata isolates from a specific cluster with expected basal positioning of the referent strain EGS 34-016 from India, while A. tenuissima EGS 34-015, A. arborescens EGS 39-128, and A. longipes EGS 30-033 positioned as the closest species into this clade, respectively. Clade II included a

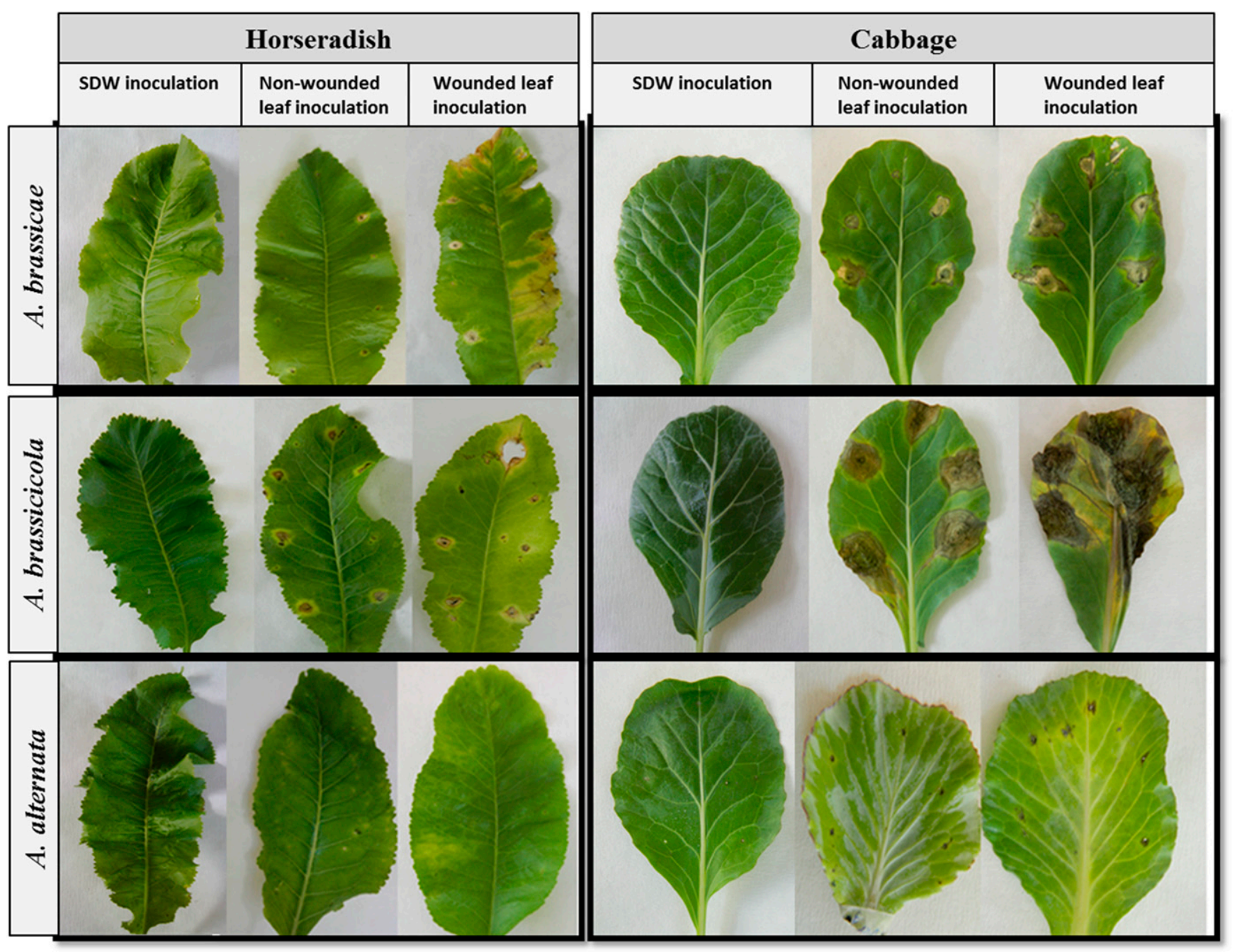

Fig. 5. Symptoms of Alternaria leaf spot disease developed 7 days after inoculation of old horseradish and cabbage leaves. SDW: plants inoculated with sterile distillated water; nonwounded and wounded leaf inoculations were done by placing a drop of a conidial suspension onto nonwounded or wounded leaves, respectively.

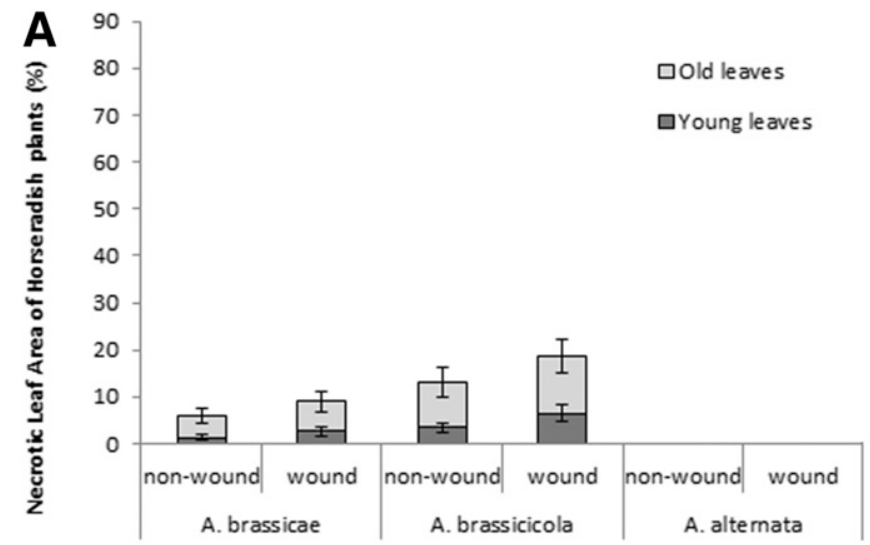

Inoculation method/Species

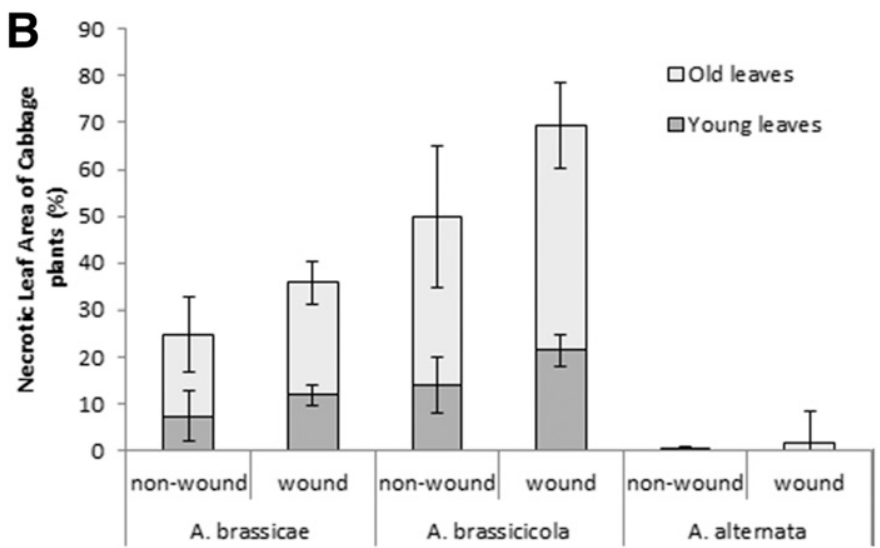

Inoculation method/Species

Fig. 6. Virulence (mean \% of necrotic leaf area and standard deviation) of $A$. brassicae, A. brassicicola, and A. alternata in inoculation assays with horseradish (A) and cabbage plants (B). Vertical bars represent standard deviation (SD) of mean. 
subclade of A. selini (EGS 25-198) and A. smyrnii (EGS 37-093), with $A$. radicina (ATCC 96831) and A. gypsophilae (CBS 107.41) grouping separately. Clade III consisted of two subclades: the first one included $A$. brassicae isolate $352 / 1$ and the reference sequence of this species, EGS 38-032; the second subclade included A. brassicicola $408 / 3$ and 429/3 from horseradish and the reference sequence EEB 2232 of this species. Clade IV consisted of three subclades comprising the reference isolates for $A$. dauci (ATCC 36613) and A.
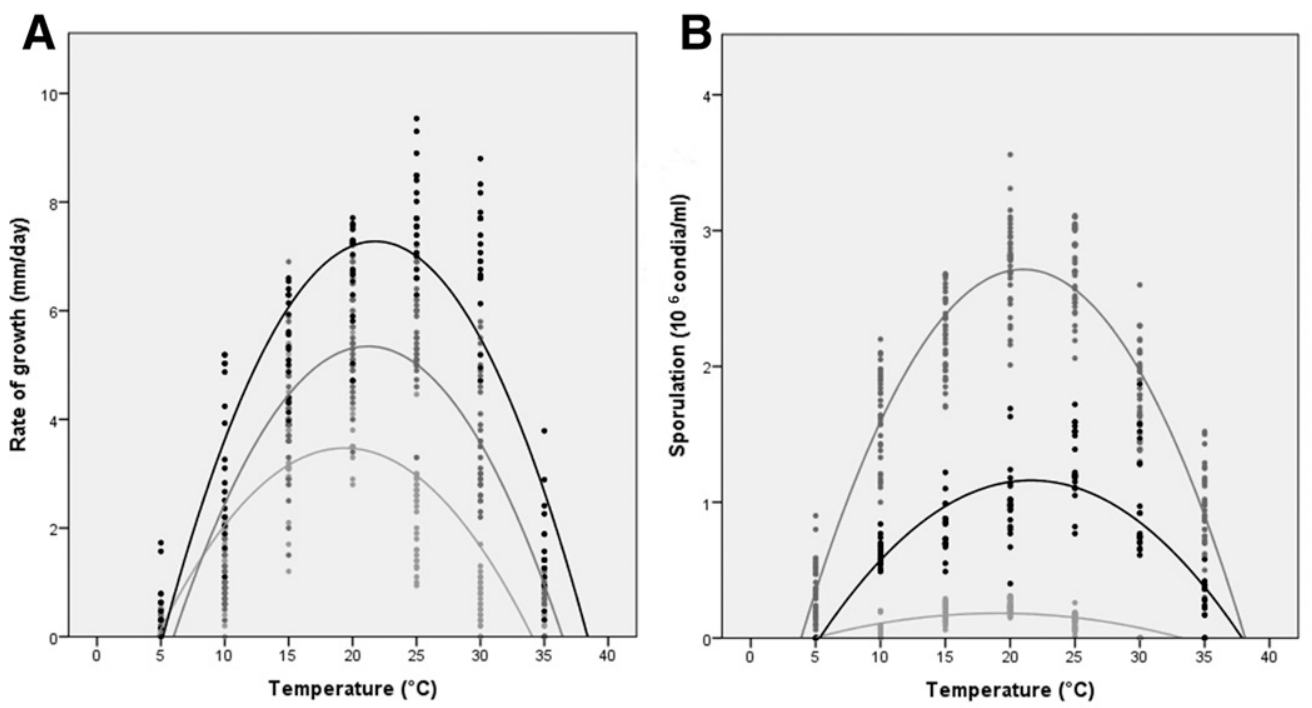

\section{Species/Curve parameters:}

\section{A. brassicae}

a) $P=0.024, R^{2}=0.653$

b) $P=0.044, R^{2}=0.548$

\section{A. brassicicola}

a) $P=0.001, R^{2}=0.868$

b) $P=0.001, R^{2}=0.782$

A. alternata

a) $P=0.000, R^{2}=0.797$

b) $P=0.001, R^{2}=0.790$

Fig. 7. Effects of temperature on the mycelial growth rate $(A)$ and sporulation $(B)$ of Alternaria species on PDA medium after 7 days. Quadratic curve parameters are mentioned in the legend $\left(P\right.$ and $\left.R^{2}\right)$ where light gray $=A$. brassicae, dark gray $=A$. brassicicola, and black $=A$. alternata curve for pictures $(A)$ and $(B)$.

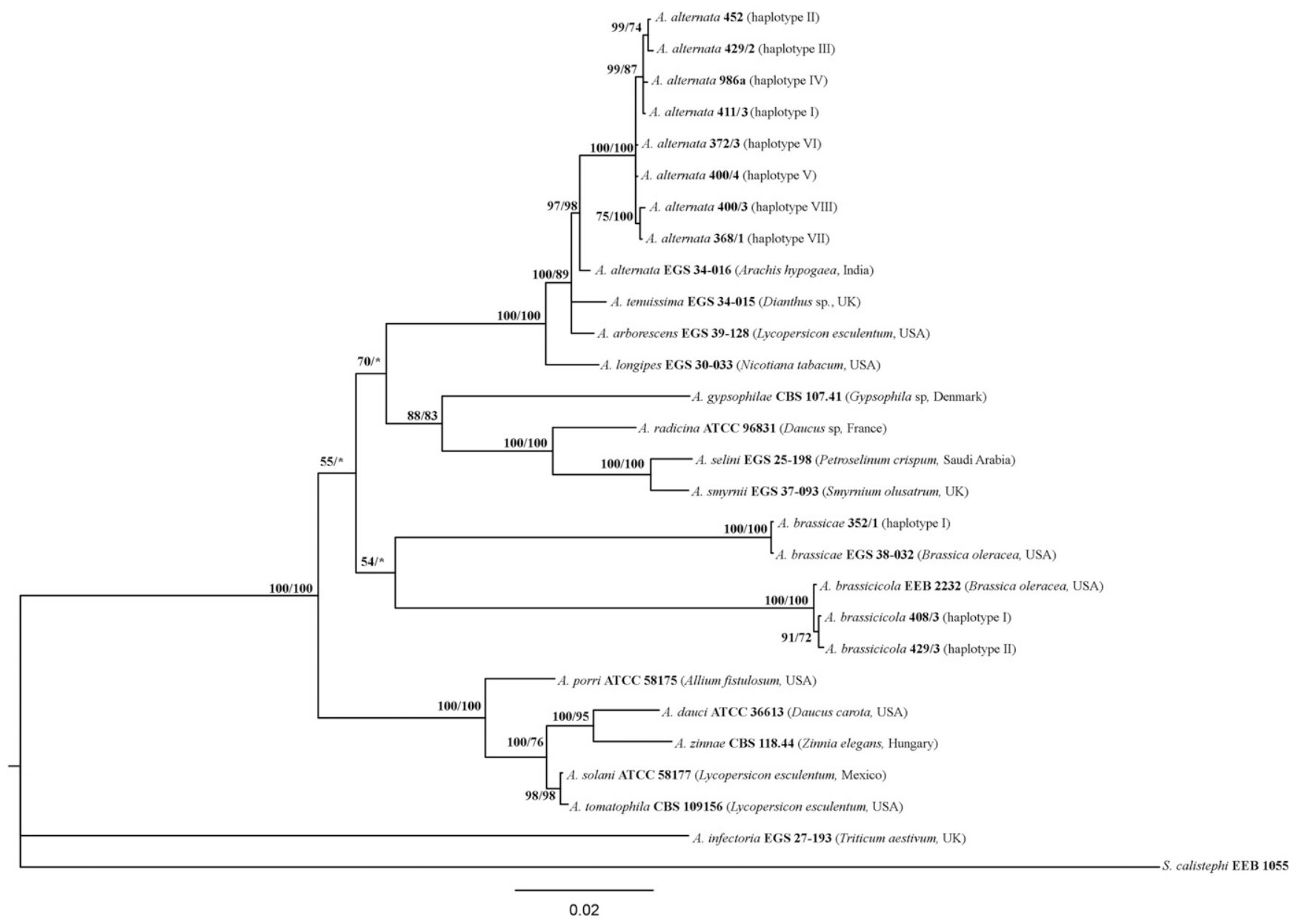

Fig. 8. Phylogenetic tree based on Bayesian and Maximum likelihood analysis using the $\mathrm{TnR}$ parameter model with discrete gamma distribution of the concatenated sequences of the ITS, Alt a 1, GAPDH and PM-ATP genes of Alternaria strains from horseradish and Alternaria reference strains from NCBI database. Bootstrap support values (expressed as percentages of 1,000 replications) are given at the nodes (Bayesian/Maximum likelihood bootstrap values of only $>50$ are shown). Bar: the estimated nucleotide substitutions per site are 0.02 . 
zinnae (CBS 118.44); A. solani (ATCC 58177) and A. tomatophila (CBS 109156); and A. porri (ATCC 58175). Sequences of A. infectoria (EGS 27-193) did not group closely to any of the other clades. Sequences of Stemphylium calistephi (EEB 1055) were used as outgroup (Fig. 8).

Haplotype network analyses. To determine evolutionary relationships among haplotypes, haplotype networks were constructed for the four concatenated sequences of the ITS, Alt a 1, GAPDH, and $P M$-ATP genes and by the most parsimonious pathways revealed three haplotype groups among isolates of $A$. brassicicola and eight across the A. alternata isolates. For A. brassicicola, haplotype 1 is a centrally positioned haplotype that is found in all regions of Serbia (but predominantly in central and western Serbia) from which the network is divided into two directions, haplotype 2 (also found in all regions of Serbia but prevalent in northern parts) and haplotype 3, of reference sequence EEB 2232. These three genetic groups differ by a single mutation in the GAPDH gene (Fig. 9A). The network of A. alternata isolates revealed eight haplotypes, based on differences in the PM-ATP gene region (Fig. 9B): haplotypes 1 to 4 are predominantly found in central and western Serbia while haplotype 1 is also detected in northern Serbia, and haplotype 2 is observed in southern and eastern Serbia; haplotypes 5 to 8 can be found only in northern Serbia and all haplotypes are separated by a single mutation.

\section{Discussion}

This work presents the first attempt to identify and characterize the Alternaria species associated with leaf spot disease on horseradish plants in Serbia. Although Alternaria pathogens have been characterized as one of the most invasive seedborne species on cruciferous plants worldwide, measures for prevention and control have been demonstrated to be insufficient when weather conditions favor infection, and as a result these pathogens have continued to represent an increasing threat in recent years (Nowicki et al. 2012; Saharan et al. 2016). Detection and characterization of Alternaria species on horseradish have been previously reported but are mostly based on observed field symptoms. A. brassicae has previously been reported on horseradish in Tanzania (Wallace and Wallace 1951), the U.S.A. (Texas, North Carolina, Iowa) (Anonymous 1960), and New Zealand (Pennycook 1989), while in Europe, it has been confirmed only in Poland (Mułenko et al. 2008). In comparison, A. brassicicola on horseradish has been confirmed only in Korea to date (Deng et al. 2015). Alternaria species have been frequently observed in horseradish growing areas in Serbia as a leaf spot pathogen that can cause complete deterioration of the leaf and $100 \%$ loss. We recently

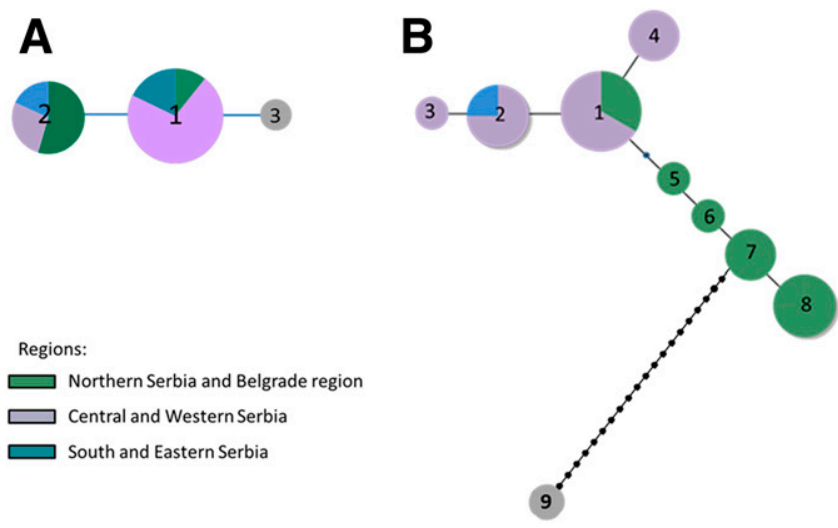

Fig. 9. Haplotype genealogical networks obtained for A, A. brassicicola isolates and B, A. alternata isolates originated from horseradish supplemented with the referent strains from the NCBI gene base under numbers 3 (EEB2232) and 9 (EGS 34016), respectively. Each haplotype is represented as a circle with number, proportional in size to the number of isolates belonging to a specific haplotype; interconnecting dots represent missing or unsampled intermediate haplotypes different by a single mutation. Different colors represent geographical regions as given in the legend. identified $A$. brassicae as the causal agent of leaf spot disease on horseradish (Blagojević et al. 2015) and this report is the first to describe A. brassicicola on horseradish in Serbia. Morphological, pathogenic, molecular, and epidemiological approaches in detection and characterization revealed for the first time the presence of three Alternaria species in horseradish crops in Serbia: A. brassicae, A. brassicicola, and A. alternata.

The number of studies concerning optimal temperatures required for growth and sporulation of pathogens are insufficient in relation to the importance that can have for effective management of the disease (Garrett et al. 2006; Humpherson-Jones 1989). Optimal growth temperatures for the Serbian A. brassicae isolates ranged between 15 to $20^{\circ} \mathrm{C}$, which is in partial agreement with previously published results from rapeseed crops in France $\left(15\right.$ to $\left.22^{\circ} \mathrm{C}\right)$, India $\left(15\right.$ to $\left.22^{\circ} \mathrm{C}\right)$, and rapeseed and cabbage crops in the U.K. (18 to $\left.23^{\circ} \mathrm{C}\right)$ and differs from the ranges reported in the Netherlands and Canada $\left(20\right.$ to $\left.24^{\circ} \mathrm{C}\right)$ (Humpherson-Jones and Phelps 1989; McDonald 1959; Louvet 1958; Saharan et al. 2016; Van Shreven 1953). Data concerning optimal temperature for growth of A. brassicicola are even more limited, but results from horseradish isolates $\left(20\right.$ to $\left.25^{\circ} \mathrm{C}\right)$ were similar to reports that higher field temperatures in the field were needed for infection of rapeseed (Degenhardt et al. 1982; McDonald 1959). The occurrence of $A$. brassicae and A. brassicicola isolates in growing areas of Serbia might be related to seasonal temperature fluctuations. In Serbia, during the summer months of June, July, and August, the average monthly temperatures range from 17 to $27^{\circ} \mathrm{C}$; consequently, $A$. brassicicola occurs as a dominant species isolated from symptomatic plants (82\%). However, during the autumn (September and October), when the average monthly temperature drops to 12 to $23^{\circ} \mathrm{C}, A$. brassicae was the predominantly isolated species $(70 \%)$. Seasonal differences in the occurrence of these two species could not be distinguished based on foliar symptoms. Additionally, A. brassicae has been described as a more common species in oilseed crops and more often found on Brassica vegetables in areas with oilseed rape production (Humpherson-Jones 1989; Köhl et al. 2010). This finding could also partially explain why A. brassicae was predominantly isolated from the horseradish in the northern region, which is the only production region for oilseed crops in Serbia.

The pathogenicity test of the three Alternaria species demonstrated that $A$. brassicicola and $A$. brassicae are both pathogenic on horseradish with $A$. brassicicola exhibiting a higher level of virulence across all experiments. Both species also caused higher disease severity on cabbage compared with horseradish. The proximity of the infected horseradish crops to the other Brassica crops could be a potentially important source of inoculum. Old leaves were more severely affected than young leaves in all cases, indicating an age-related difference in the susceptibility of the tissue. A. alternata was also isolated from necrotic tissue, but inoculation experiments indicated that it was a weak pathogen on cabbage and did not cause disease on horseradish.

Although phenotypic differences have been reported previously (Bock et al. 2002; Lawrence et al. 2016; Simmons 2007), significant differences in the morphology were not observed among our $A$. brassicae isolates. Only minor differences in mycelia color were observed, varying from light brown to white on V8 medium. Previous studies of $A$. brassicae based on the RAPD profile analysis showed genetic uniformity of isolates with diverse geographical origins (Cooke et al. 1998). Low levels of evolutionary selection through competitive pressure, or its complete absence, could be the cause of this phenotype and genotype stability (Cooke et al. 1998; Humpherson-Jones 1992). Phylogenetic analyses based on ITS, Alt a 1, GAPDH, and PM-ATP gene sequences supported homogeneity among $A$. brassicae strains from horseradish in Serbia by grouping these isolates in the same clade, with reference $A$. brassicae strain EGS 38-032 originating from the U.S.A. Because of the relatively small number of isolates, the distribution of genetic variation between different continents, regions, and individuals is difficult to assess and a more detailed study with different genetic markers is required. Isolates of $A$. brassicicola showed a complete lack of morphological diversity, as previously reported (Bock et al. 2002). 
However, unlike $A$. brassicae, phylogenetic analysis revealed the presence of three haplotype groups of A. brassicicola and divergence of the isolates originating from Serbia and reference $A$. brassicicola strain EEB 2232 from the U.S.A. The obtained results are in concordance with similar studies that confirmed high levels of genetic diversity for A. brassicicola populations (Avenot et al. 2005; Bock et al. 2002, 2005; Cooke et al. 1998; Kreis et al. 2016; Linde et al. 2010). Evolutionary mechanisms that lead to intraspecific genetic variability have been reported in France, England, Canada, and the U.S.A, although not fully confirmed indications of recombination have been suggested (Kreis et al. 2016). Both the morphological and genetic variability observed for the Serbian A. alternata strains are characteristic of other similar populations. The typical morphological diversity (Simmons 2007) was observed among isolates from Serbia. Additionally, genetic intraspecific diversity was revealed by the presence of 8 haplotypes that grouped into two geographical regions: northern Serbia (Pannonian plain), consisting of haplotypes 5, 6, 7, and 8; and central and western Serbia (hilly terrain) isolates consisting of haplotypes 1, 2, 3, and 4. Haplotype 1, the central haplotype of the network, was a common haplotype observed in northern Serbia, while haplotype 2 was the most commonly detected in southern Serbia. A difference in population genetic and geographical distribution of A. alternata species suggests that spore dispersal by wind and rain is not the primary means of spreading these agents as was previously thought. Since horseradish is usually planted by cuttings, seedborne diseases are rare, and transmissions are probably due to diseased plant material and scattered infection propagules from other hosts followed by rapid host/pathogen adaptation. Some authors assume that genetic diversity is maintained by mutation, uniform host selection, extensive dispersal, or the existence of a cryptic sexual stage (Aradhya et al. 2001; Morris et al. 2000).

The aggressive pathogenic impact of A. brassicicola and A. brassicae is amended by the unclear pathogenic capability of A. alternata. Samples from Serbia compared with the isolates originating from other parts of Europe, and even from other continents, have shown that following pathogenic, morphological, and genetic traits, subjected Alternaria species do not express host specificity and thus should be treated as multicrop pathogens. Although seemingly equally involved in the leaf spot diseases of horseradish, these pathogens do have temporal differences in their appearance and impact, which should be noted in future prevention and control management strategies. The extensive genetic methodology that combined four gene regions for the first time revealed intraspecific divergence of A. alternata with spatially defined differentiation. The present research has aimed to provide a better understanding of the epidemiology and morphological and genetic diversity of leaf spot diseases in Brassica hosts caused by Alternaria species. Although low genetic diversity has been detected comparing very distant territories, testing of the new genetic markers combined with more Brassica production regions that have not been subjected to this type of research to date may help to characterize the diversity and pathogenicity of isolates. Establishing a global phylogeographical framework is vital to integrate into the hypothesis of evolutionary potential, pathogenicity, and distribution and developing specific disease management strategies for the genus Alternaria.

\section{Literature Cited}

Agneta, R., Möllers, C., and Rivelli, A. R. 2013. Horseradish (Armoracia rusticana), a neglected medical and condiment species with a relevant glucosinolate profile: a review. Genet. Resour. Crop Evol. 60:1923-1943.

Amatulli, T., Fanelli, M., Moretti, F., Mule, A., and Logrieco, A. 2013. Alternaria species and mycotoxins associated to black point of cereals. Mycotoxins. 63: 39-46.

Andrew, M., Peever, T. L., and Pryor, B. M. 2009. An expanded multilocus phylogeny does not resolve morphological species within the small-spored Alternaria species complex. Mycologia 101:95-109.

Anonymous. 1960. Index of Plant Diseases in the United States. U.S.D.A. Agricultural Handbook 165:1-531.

Aradhya, M. K., Chan, H. M., and Parfitt, D. E. 2001. Genetic variability in the pistachio late blight fungus, Alternaria alternata. Mycol. Res. 105:300-306.

Avenot, H., Simoneau, P., Iacomi-Vasilescu, B., and Bataillé-Simoneau, N. 2005. Characterization of mutations in the two-component histidine kinase gene
AbNIK1 from Alternaria brassicicola that confer high dicarboximide and phenylpyrrole resistance. Curr. Genet. 47:234-243.

Berbee, M. L., Pirseyedi, M., and Hubbard, S. 1999. Cochliobolus phylogenetics and the origin of known, highly virulent pathogens, inferred from ITS and glyceraldehyde-3-phosphate dehydrogenase gene sequences. Mycologia 91: 964-977.

Blagojević, J., Ignjatov, M., Vukojević, J., and Ivanović, Ž. 2015. First report of horseradish leaf spot caused by Alternaria brassicae in Serbia. Plant Dis. 99:730.

Bock, C. H., Thrall, P. H., Brubaker, C. L., and Burdon, J. J. 2002. Detection of genetic variation in Alternaria brassicicola using AFLP fingerprinting. Mycol. Res. 106:428-434.

Bock, C. H., Thrall, P. H., and Burdon, J. J. 2005. Genetic structure of populations of Alternaria brassicicola suggests the occurrence of sexual recombination. Mycol. Res. 109:227-236.

Chauhan, J. S., Badoni, A., Singh, N. I., and Ali, S. 2009. Effect of Alternaria on some members of family Brassicaceae of Garhwal Himalaya. N. Y. Sci. J. 2 $80-85$.

Clement, M., Posada, D., and Crandall, K. A. 2000. TCS: a computer program to estimate gene genealogies. Mol. Ecol. 9:1657-1659.

Cooke, D. E. L., Forster, J. W., Jenkins, P. D., Jones, D. G., and Lewis, D. M. 1998 Analysis of intraspecific and interspecific variation in the genus Alternaria by the use of RAPD-PCR. Ann. Appl. Biol. 132:197-209.

Darriba, D., Taboada, G. L., Doallo, R., and Posada, D. 2012. jModelTest 2: more models, new heuristics and parallel computing. Nat. Methods 9:772.

Degenhardt, K. J., Petrie, G. A., and Morrall, R. A. A. 1982. Effects of temperature on spore germination and infection of rapeseed by Alternaria brassicae, A. brassicicola, and A. raphani. Can. J. Plant Pathol. 4:115-118.

Deng, J. X., Li, M. J., Paul, N. C., Lee, J. H., Cho, H. S., Lee, H. B., and Yu, S. H. 2015. Alternaria species associated with araliaceous plants in Korea. Mycol. Prog. 14:31.

Eastburn, D. M., and Chang, R. J. 1994. Verticillium dahliae: A causal agent of root discoloration of horseradish in Illinois. Plant Dis. 78:496-498.

Gannibal, P. B., Orina, A. S., Mironenko, N. V., and Levitin, M. M. 2014 Differentiation of the closely related species, Alternaria solani and A. tomatophila, by molecular and morphological features and aggressiveness. Eur. J. Plant Pathol. 139:609-623.

Garrett, K. A., Dendy, S. P., Frank, E. E., Rouse, M. N., and Travers, S, E. 2006 Climate change effects on plant disease: genomes to ecosystems. Annu. Rev. Phytopathol. 44:489-509.

Gorecka, K., and Lehmann, P. 2001. Infectious diseases of horseradish (Cochlearia armoracia L.) in Poland. Plant Breed. Seed Sci. 45:55-64.

Hong, S. G., Cramer, R. A., Lawrence, C. B., and Pryor, B. M. 2005. Alt a1 allergen homologs from Alternaria and related taxa: analysis of phylogenetic content and secondary structure. Fungal Genet. Biol. 42:119-129.

Humpherson-Jones, F. M. 1985. The incidence of Alternaria spp. and Leptosphaeria maculans in commercial brassica seed in the United Kingdom. Plant Pathol. 34:385-390.

Humpherson-Jones, F. M. 1989. Survival of Alternaria brassicae and Alternaria brassicicola on crop debris of oilseed rape and cabbage. Ann. Appl. Biol. 115:45-50.

Humpherson-Jones, F. M. 1992. Epidemiology and control of dark leaf spot of brassicas. Alternaria: biology, plant diseases, and metabolites. J. Chelkowski and A. Visconti, eds. Elsevier, Amsterdam, the Netherlands.

Humpherson-Jones, F. M., and Phelps, K. 1989. Climatic factors influencing spore production in Alternaria brassicae and Alternaria brassicicola. Ann. Appl. Biol. 114:449-458

Huson, D. H., and Bryant, D. 2006. Application of phylogenetic networks in evolutionary studies. Mol. Biol. Evol. 23:254-267.

Köhl, J., Van Tongeren, C. A. M., Groenenboom-de Haas, B. H., Van Hoof, R. A., Driessen, R., and Van Der Heijden, L. 2010. Epidemiology of dark leaf spot caused by Alternaria brassicicola and A. brassicae in organic seed production of cauliflower. Plant Pathol. 59:358-367.

Kreis, R. A., Dillard, H. R., and Smart, C. D. 2016. Population diversity and sensitivity to azoxystrobin of Alternaria brassicicola in New York State. Plant Dis. 100:2422-2426.

Lawrence, D. P., Gannibal, P. B., Dugan, F. M., and Pryor, B. M. 2014. Characterization of Alternaria isolates from the infectoria species-group and a new taxon from Arrhenatherum, Pseudoalternaria arrhenatheria sp. nov. Mycol. Prog. 13:257-276.

Lawrence, D. P., Gannibal, P. B., Peever, T. L., and Pryor, B. M. 2013. The sections of Alternaria: Formalizing species-groups concepts. Mycologia 105:530-546.

Lawrence, C. B., Mitchell, T. K., Craven, K. D., Cho, Y. R., Cramer, R. A., and Kim, K. H. 2008. At death's door: Alternaria pathogenicity mechanisms. Plant Pathol. J. 24:101-111.

Lawrence, D. P., Rotondo, F., and Gannibal, P. B. 2016. Biodiversity and taxonomy of the pleomorphic genus Alternaria. Mycol. Prog. 15:3.

Leigh, J. W., and Bryant, D. 2015. PopArt: full-feature software for haplotype network construction. Methods Ecol. Evol. 6:1110-1116.

Li, X., and Kushad, M. 2004. Correlation of glucosinolates content to myrosinase activity in horseradish (Armoracia rusticana). J. Agric. Food Chem. 52: 6950-6955.

Linde, C. C., Liles, J. A., and Thrall, P. H. 2010. Expansion of genetic diversity in randomly mating founder populations of Alternaria brassicicola infecting Cakile maritima in Australia. Appl. Environ. Microbiol. 76:1946-1954. 
Louvet, J. 1958. The black spot disease of colza, Alternaria brassicae. C. R. Acad. Agric. J. 44:694-701.

McDonald, W. C. 1959. Gray leaf spot of rape in Manitoba. Can. J. Plant Sci. 39:409-416.

Morris, P. F., Connolly, M. S., and St Clair, D. A. 2000. Genetic diversity of Alternaria alternata isolated from tomato in California assessed using RAPDs. Mycol. Res. 104:286-292.

Mułenko, W., Majewski, T., and Ruszkiewicz-Michalska, M. 2008. A Preliminary Checklist of Micromycetes in Poland. W. Szafer Institute of Botany, Polish Academy of Sciences, Kraków, Poland.

Nowicki, M., Nowakowska, M., Niezgoda, A., and Kozik, E. 2012. Alternaria black spot of crucifers: symptoms, importance of disease, and perspectives of resistance breeding. Veg. Crops Res. Bull. 76:5-19.

Peever, T. L., Su, G., Carpenter-Boggs, L., and Timmer, L. W. 2004. Molecular systematics of citrus-associated Alternaria species. Mycologia 96:119-134.

Pennycook, S. R. 1989. Plant Diseases Recorded in New Zealand. Plant Diseases Division, DSIR, Auckland, New Zealand.

Percich, J. A., and Johnson, D. R. 1990. A root rot complex of horseradish. Plant Dis. 74:391-393

Perlaki, Z., and Djurovka, M. 2009. Horseradish root yield depending on organic and mineral fertilizers. Contemp. Agric. 58:106-111.

Pleysier, C. E., Bayliss, K. L., Dell, B., and Hardy, G. E. St. J. 2006. Temperature, humidity, wounding and leaf age influence the development of Alternaria alternata lesions on leaves of Paulownia fortunei. Australas. Plant Pathol. 35:329-333.

Pryor, B. M., and Bigelow, D. M. 2003. Molecular characterization of Embellisia and Nimbya species and their relationship to Alternaria, Ulocladium and Stemphylium. Mycologia 95:1141-1154.

Pryor, B. M., and Michailides, T. J. 2002. Morphological, pathogenic, and molecular characterization of Alternaria isolates associated with Alternaria late blight of pistachio. Phytopathology 92:406-416.

Rambaut, A. 2012. FigTree v1.4. Molecular evolution, phylogenetics and epidemiology. Institute of Evolutionary Biology, University of Edinburgh, Edinburgh, UK.

Rambaut, A., and Drummond, A. J. 2009. TRACER: MCMC Trace Analysis Tool Version v1.5.0. University of Oxford.

Ronquist, F., and Huelsenbeck, J. P. 2003. MrBayes 3: Bayesian phylogenetic inference under mixed models. Bioinformatics 19:1572-1574.

Runa, F., Park, M. S., and Pryor, B. M. 2009. Ulocladium systematics revisited: phylogeny and taxonomic status. Mycol. Prog. 8:35-47.

Saharan, G. S., Mehta, N., and Meena, P. D. 2016. Alternaria Diseases of Crucifers: Biology, Ecology and Disease Management. Springer, Singapore. doi.org/10.1007/978-981-10-0021-8
Saharan, G. S., Mehta, N., and Sangwan, M. S., eds. 2005. Diseases of Oilseed Crops. Indus Publishing, New Delhi, India.

Schneider, C. A., Rasband, W. S., and Eliceiri, K. W. 2012. NIH Image to ImageJ: 25 years of image analysis. Nat. Methods 9:671-675.

Shaw, D. A., Adaskaveg, J. E., and Ogawa, J. M. 1990. Influence of wetness period and temperature on infection and development of shothole disease of almond caused by Wilsonomyces carpophilus. Phytopathology 80:749-756.

Simmons, E. G. 2007. Alternaria: an identification manual. CBS Biodiversity Series 6. Centraalbureau voor Schimmelcultures, Utrecht, The Netherlands.

Tamura, K., Stecher, G., Peterson, D., Filipski, A., and Kumar, S. 2013. MEGA6: Molecular Evolutionary Genetics Analysis Version 6.0. Mol. Biol. Evol. 30: 2725-2729.

Tedeschi, P., Leis, M., Pezzi, M., Civolani, S., Maietti, A., and Brandolini, V. 2011. Insecticidal activity and fungitoxicity of plant extracts and components of horseradish (Armoracia rusticana) and garlic (Allium sativum). J. Environ. Sci. Health B 46:486-490.

Van Shreven, D. A. 1953. Alternaria, Stemphylium and Botrytis infection of colza (Brassica napus). Tizdschr. Planterzickten 59:105-136.

Verhoeven, D. T. H., Verhagen, H., Goldbohm, R. A., Brant, P. A. V. D., and Poppel, G. V. 1997. A review of mechanisms underlying anticarcinogenicity by brassica vegetables. Chem. Biol. Interact. 103:79-129.

Wallace, G. B., and Wallace, M. M. 1951. Tanganyika fungus list: recent records. No. XV. Mycological Circular. Department of Agriculture, Tanganyika, 31.

White, T. J., Bruns, T., Lee, S., and Taylor, J. 1990. Amplification and direct sequencing of fungal ribosomal RNA genes for phylogenetics. Pages 315-322 in: PCR Protocols: A Guide to Methods and Applications. M. A Innis, D. H. Gelfand, J. J. Sninsky, and T. J. White, eds. Academic Press, San Diego, CA.

Woudenberg, J. H. C., Groenewald, J. Z., Binder, M., and Crous, P. W. 2013 Alternaria redefined. Stud. Mycol. 75:171-212.

Woudenberg, J. H. C., Truter, M., Groenewald, J. Z., and Crous, P. W. 2014. Large spored Alternaria pathogens in section Porri disentangled. Stud. Mycol. 79:1-47.

Yu, J., Cafarov, I. H., and Babadoost, M. 2016. Morphology, molecular identity, and pathogenicity of Verticillium dahliae and V. longisporum associated with internally discolored horseradish roots. Plant Dis. 100:749-757.

$\mathrm{Yu}$, J. M., and Babadoost, M. 2013. Occurrence of Fusarium commune and $F$. oxysporum in horseradish roots. Plant Dis. 97:453-460.

Zhu, X. Q., and Xiao, C. L. 2015. Phylogenetic, morphological, and pathogenic characterization of Alternaria species associated with fruit rot of blueberry in California. Phytopathology 105:1555-1567. 